INFORMATION

\title{
NAVIGATING THE INTERCULTURAL CLASSROOM
}

Lindholm, T., \& Mednick Myles, J.

\author{
Alexandria, Virginia: TESOL International Association, 2019
}

\author{
Hoang Thi Hanh* \\ Faculty of Linguistics and Cultures of English Speaking Countries \\ University of Languages and International Studies, VNU \\ Pham Van Dong, Cau Giay, Hanoi, Vietnam
}

Received 13 June 2019

Revised 31 December 2019; Accepted 14 February 2020

\begin{abstract}
Intercultural communication is usually a compulsory component of a TESOL training course. However, it is usually about intercultural communication generally in various contexts. The book Navigating the intercultural classroom bridges intercultural communication especially intercultural competence into language classes by reviewing theoretical background and suggesting specific, concrete practices to enhance both students' and teachers' inner growth and awareness of language together with intercultural competence. It was written by two experienced ESOL teachers (teaching English to speakers of other languages) and curriculum developers, Tuula Lindholm and Johanne Mednick Myles, teaching English in multicultural communities. The book was inspired and derived from their experience of teaching international students, from real-life contexts for intercultural communication.

Foreworded by Deardorff, an expert in intercultural competence, the book consists of six chapters. Each chapter starts with an overview and a list of questions guiding
\end{abstract}

Tel.: 84-905598994

Email: hanhhtulis@gmail.com the readers on thinking about the topic before leading the readers to the theory part. The theoretical foundation parts in each chapter bring together a synthesis of current perspectives on intercultural competence in an easily understandable but comprehensive way, which is accessible and friendly to ESOL teachers who do not need to be specialists in intercultural communication and training. Those who specialize in intercultural communication teaching and training can also find this part a nice synthesis of different approaches including social scientific, interpretative and critical (Oetzel, Pant \& Rao, 2016), and how such approaches can be extracted to apply in language teaching.

The practical examples of intercultural activities suggested in each chapter are urgently needed for ESOL instructors in teaching students of various cultural backgrounds. They are needed because they are devised based on the inter-relation of multiple intercultural communication approaches, taking students' language levels and cultural and psychological contexts into consideration. In other words, the activities are not just listed as inventory list of items, but they go deeply with their hows and whys. Specifically, in designing 
the intercultural communication activities in language classroom, Lindholm and Mednick Myles (2019) have adapted The 6 Principles for Exemplary Teaching of English Learners developed by TESOL International Association (2018) into five principles including:

- respect, affirm, and promote students' home languages, cultural knowledge, and experiences;

- learn about students' cultural and geographic backgrounds and seek to understand how their backgrounds have influenced their cultural beliefs and behaviors;

- be mindful of situations that require an intercultural perspective to fully understand the message;

- celebrate multilingualism, multiculturalism, and diversity; and

- guide students to be "interculturalists" and global citizens. (p. viii)

For this reason, the activities suggested are not only useful for ESOL classrooms but also applicable for intercultural communication courses for those studying TESOL program. Though the authors tentatively claim only their experience in and the application of the practices North American contexts with international students and immigrants, readers may find their suggestions applicable in other English as a Foreign Language (EFL) contexts as well.

In chapter 1 , Intercultural communication and teaching culturally diverse learners, the authors review the major concepts in intercultural communication including culture, identity, language, behaviors, cultural dimensions, stereotypes, ICC, cultural adaptation and the relationship among these elements in intercultural communication and ICC development. Even though the concepts cited and reviewed mostly come from social scientific approach, the authors address the topic tentatively and critically to avoid making essentialist assumptions of cultural similarities and differences. The part on dealing with stereotypes appeals more to critical perspective. Based on such critical review, the authors argue for the whys and map the hows to include intercultural components in ESOL teaching and learning. The classroom best practices part suggests various activities which are especially applicable for the contexts in which multicultural students find themselves in the new environment. They aim to empathize with and accommodate students during their cultural transition and identity development process. At the same time, they can promote teachers' professional development since understanding learners could be and should be the most important component of teachers' competence (Le, 2018). These suggested activities, strongly founded from the authors' teaching and consulting experience, though aim at students living and studying in new cultures, can also be applied for orientation courses preparing students before studying abroad and other students in language and/or intercultural communication course.

Chapter 2 discusses the role of intercultural communicative competence (ICC) in language teaching and learning. In the theoretical part, the authors discuss the relationship between language and culture, the relevance of pragmatics and intercultural pragmatics in ESOL curriculum and review some ICC models and the measurement of ICC. The authors analyze how ICC elements can be found in the Canadian Language Benchmarks, the Massachusetts Framework and the Common European Framework. In trying to suggest ways to incorporate ICC into ESOL curriculum, the authors argue that doing needs analysis on the themes and topics for the program is necessary but not yet sufficient. They suggest taking into account the interactional process and the interpretation of interaction through dialogue, discussion and reflection in engaging learners in thinking about and developing their ICC. From such argument, the authors suggest best classroom practices such as creating opportunities for meaningful interaction, cultural learning, storytelling about culture and 
identity, cultural knowledge comparison and self-reflection about cultural behaviours.

Titled "teachers as intercultural informant and classroom strategist," chapter 3 outlines how teachers can be reflective on their own beliefs and practices to keep learning and to function as intercultural informant and strategically maneuver the classroom to exploit the best of the resources that multicultural students bring to the ESOL learning environment to resolve conflicts and to promote learning. In the theoretical part, the authors review the underlying culture, beliefs and biases behind teachers' identity and what it means to be cultural informants and cultural strategists for both native and non-native English teachers. They then provide practical suggestion on dealing with cultural conflicts between teachers and students and among students and capitalizing on cultural conflicts as learning opportunities for both teachers and students. They also suggest step-by-step guide to reflecting and understanding one's cultural identity, which can be applied not for both teachers and students' cultural learning.

Chapter 4 describes challenges of both students and teachers in English for Academic Purposes (EAP) program and the cultural expectations of Western education from international students. The authors argue that improving intercultural awareness is a twoway process, in which the responsibilities of improving one's ICC lie not only in students but also in teachers and supporting staff. The authors also suggest various strategies and activities to accommodate students in dealing with the requirements of critical thinking, assignments and avoiding plagiarism such as using multiple forms of expressing knowledge, scaffolding students' critical thinking, training students in appropriate spoken and written discourse for academic encounters. Besides, they also suggest having staff and faculty trained in intercultural awareness and communication.

Chapter 5 discusses cultural integration in employment preparation programs.
The authors argue for the necessity of intercultural communicative competence for ESOL learners to join the workforce as ICC is an important part of soft skills required in employment markets. They further discuss how cultural values and beliefs influence intercultural work experience, communication, networking, mentoring, and how teachers can model emotional intelligence in the classroom. The classroom best practice section suggests activities to prepare learners for job interviews, negotiating, providing constructive critical feedback and holding small talks. The activities suggested aim to develop ICCs and skills for the workplace and to help ESOL learn to establish a workplace cultural/professional identity.

Chapter 6 deals with technology and computer-mediated communication. Based on theoretical perspectives on multiliteracies and their connection to English learning and ICC development, the authors suggest how to use social media, and other online systems to facilitate student online communication, collaboration and develop online communication skills. Practical skills to develop ICC include writing email, chatting, and video conferencing to complete collaborative project. The authors also suggest interpreting and critically analyzing authentic texts to acquire cultural knowledge and develop necessary skills to for effective online communication.

In the conclusion, the authors reemphasize the importance of integrating intercultural competences in ESOL education. They emphasize that besides an understanding of theory, the integration requires a reconceptualization of the nature of ESOL teaching and learning, a change in the teachers' mindset about our role as cultural informants and strategist and a constant reconsideration of communication situations in terms of underlying cultural values and beliefs. These, they believe, help maintain diversity and inclusion practices and support learners in their process of understanding how 
culture shapes communication.

The book ends with five appendices providing updated additional resources related to intercultural communication for teachers' reference and consultation. In appendix A, understanding cultural preferences, various cultural dimensions are synthesized into a full length list of cultural preferences supposed to influence communication. Appendix B lists several models of intercultural competence including those by Deardorff (2006), Bennett (2004, 2014) and Arasaratnam (2009). Appendix C lists six principles of culture based on Atkinson's (1999). Appendix D suggests ways of observing and analyzing cultural behaviours adapted from the Massachusetts Department of Education, Adult and Community Learning Services (2005) and Alberta Teachers of English as a Second Language (2009). The last appendix is a figure summarizing workplace communication activities and the language required for them. This figure is taken from a larger research project of one of the authors (Mednick Myles, 2005)

The distinctive feature of this book is its meaningful practical suggestions to apply in ESOL teaching, learning and curriculum design based on sound understanding of relevant theories and research of both ESOL concepts and practices and intercultural communication literature. However, the book also has some minor drawbacks.

One drawback of the book is that sometimes the authors refer to native speakers as a target source of reference for learners. This is understandable since the authors are teaching non-native students who need to adapt to the larger host culture of North American contexts.

Another drawback is that some interpretation of learners' culture might need rechecking. For example, in the last section of chapter 6, their comments and analysis on students' email might need revising. The emails read as:

Respected mam,
Could please recheck my essay. I am kind of thinking of better grade for the last one, if possible please forward me feedback for my essay. Please let me know where I was week. Your's faithfully (p. 167)

Dear Ms. Tuula,

I am very thankful to you for giving me second chance for the essay assignment. Please find attached herewith essay assignment and obliged. I'm not sure I pass hope so (p. 168)

The interpretation of the authors which follow the two citations of the email includes:

This student's writing could also be a loose translation from the first language and comes across rather bossy while it also makes us smile because we can see here the attempt made by the student to try to influence the professor about marking the essay. (p. 168)

It might be true that the students' email could be a loose translation from the first language. It may also come across rather bossy, but since it may not be the students' intention to be bossy, the authors may add "come across rather bossy to us" to specify possible unintended effects of the communication due to different cultural expectation and interpretation. Furthermore, from my own cultural perspective, which might be closer to the students' in cultural position, I do not think that the students attempted to influence the professor about marking the essay in these two emails. The author use "we can see here the attempt" frames it to sound like a fact that visibly exists rather than a possible misinterpretation. An addition of a "smile" might also complicate this misunderstanding and misappreciation. In the following paragraph, still discussing these two emails, the authors write:

Nevertheless, the email also shows respect for a professor by a student who sees the teacher in a much higher authority/ power position. The content of the message reveals the student's own view of his or her position as someone who is "weak" and in need of feedback and help. The writing here reveals clearly a perception of positions in a 
hierarchy that reflects the cultural values the learner has grown up with in a society that is much more socially stratified. This is not surprising, as this writer is originally from India. (p. 168),

which sounds valid. However, let's look at the following sentences:

It is not uncommon in India for families to attempt to use connections with people in positions of authority who can help them affect the outcome of their children's education or get access to coveted university and college positions. Though some of us have grown up with cultural values that condemn bribery and nepotism, we need to recognize that these practices are commonplace in many other cultures and countries in the world.

In these sentences, the authors might just mean to describe cultural differences. However, though we do not know how widespread or common such practices that they describe are, people in India possibly do not support bribery and nepotism either. Indian people may also condemn bribery and nepotism as much as the authors do. Framing it this way and adding it after the interpretation of the examples of the students' emails might make the authors sound to us like being ethnocentric and using prejudice to judge students while the authors might only intend provide cultural background to promote cultural understanding.

As for presentation, a minor issue with the book is that it does not have a navigation view and the subsections are not numbered. This sometimes makes it hard to go back and forth to look for certain sections that the readers want to find. In addition, while naming one part as theoretical perspective and another equal part as classroom best practices, other parts in between these sections sometimes sound rather confusing because readers may not find it clear whether they belong to theory or practice section.

However, the book is a valuable resource for ESOL practitioners in both English as second language and English as a foreign language contexts, and not just for ESOL teachers but also teachers and trainers of intercultural communication. Teachers who prepare students for intercultural communication can also envision what contexts and situations students may find themselves in when joining intercultural academic and working environments based on suggestions in the book. Language and intercultural communication teacher trainers and curriculum developers of various backgrounds can also find this book a useful reference during their practices and program design.

\section{References}

Le, V.C. (2018). Remapping the teacher knowledgebase of language teacher education: A Vietnamese perspective. Language Teaching Research. doi: 10.1177/1362168818777525

Lindholm, T., \& Mednick Myles, J. (2019). Navigating the Intercultural Classroom. Alexandria, Virginia: TESOL International Association.

Oetzel, J., Pant, S., \& Rao, N. (2016). Methods for intercultural communication research. In Oxford research encyclopedia of communication. doi: 10.1093/acrefore/9780190228613.013.202 